\title{
Isolation of Cultivation-Resistant Oomycetes, First Detected as Amplicon Sequences, from Roots of Herbicide-Terminated Winter Rye
}

Matthew G. Bakker, Thomas B. Moorman, and Thomas C. Kaspar, U.S. Department of Agriculture-Agricultural Research Service (USDA-ARS), National Laboratory for Agriculture \& the Environment, 1015 N. University Blvd., Ames, IA 50011; and Daniel K. Manter, USDA-ARS, Soil Management and Sugarbeet Research Unit, 2150 Centre Ave., Building D, Suite 100, Fort Collins, CO 80526

Accepted for publication 12 January 2017.

\section{ABSTRACT}

The dynamics of microbial communities associated with dying cover crops are of interest because of potential impacts on disease in a subsequent crop, and because of the importance of microbial activity on plant residue to soil organic matter dynamics and nutrient cycling. We used high throughput amplicon sequencing to characterize the composition and structure of oomycete and fungal communities associated with a rye cover crop, and to track their community dynamics in the first several weeks after herbicide was applied to terminate the cover crop. The dominant oomycetes associated with cereal rye roots were Pythium volutum, Pythium sp. F86 (an unknown species within clade $\mathrm{B}$ ), and Lagena radicicola. Because $P$. volutum is sensitive to common additives in isolation media, and $L$. radicicola is an obligate intracellular parasite, a unique aspect of this work is to reveal the dominance of oomycete taxa that would have been missed entirely under a traditional cultivation-based approach. Based on first detection in an amplicon sequencing survey, we were able to isolate $P$. volutum and Pythium sp. F86. We demonstrate that both species are pathogenic on corn, and that corn seedlings grown in the field following a rye cover crop show elevated rates of infection by $P$. volutum, highlighting a potential disease risk associated with cover cropping. $P$. volutum and Pythium sp. F86 exhibited contrasting spatial patterns of abundance, with nearly complete turnover of the dominant species across the field site. In contrast to the strong spatial structuring and low diversity of oomycete communities, fungal communities associated with a cereal rye cover crop were more diverse and dynamic, with some displacement of basidiomycetes by ascomycetes over time. Several plant pathogens, as well as putative beneficial organisms, were detected among fungal communities associated with rye roots. This work sheds light on microbial community dynamics on dying host plants, highlights the power of cultureindependent microbial community assessment to yield new insights, and suggests the need for informed management to reduce seedling disease risk in corn following rye cover crops.

Additional keywords: agriculture, ecology, plant pathology, rhizosphere and phyllosphere, soil ecology.
Plants impact the identities and abundances of microbes that are present in the phytobiome and alter the trajectory of microbial

Corresponding author: M. G. Bakker; E-mail address: Matt.Bakker@ars.usda.gov

Current address of M. G. Bakker: USDA-ARS, Mycotoxin Prevention \& Applied Microbiology Research Unit, 1815 N. University St., Peoria, IL 61604.

Mention of trade names or commercial products is solely for the purpose of providing specific information and does not imply recommendation or endorsement by the U.S. Department of Agriculture. This article was the work of U.S. Government employees engaged in their official duties and is exempt from copyright.

*The $\boldsymbol{e}$-Xtra logo stands for "electronic extra" and indicates that three supplementary material files are published online.

This article is in the public domain and not copyrightable. It may be freely reprinted with customary crediting of the source. The American Phytopathological Society, 2017. community development (Bakker et al. 2012). In turn, the microbiota associated with plants perform important services that can impact plant performance (Bakker et al. 2010; Redman et al. 2002). In agricultural systems, plant-driven impacts on soil microbiomes are among the primary motivations for crop rotation. There is a rich body of literature detailing the impacts of living host plants on the composition and structure of microbial communities in the rhizosphere (Peiffer et al. 2013), phyllosphere (Bai et al. 2015), and internal plant tissues (Lundberg et al. 2012). However, there has been less attention paid to the impacts of dying plants and their residues on associated microbiomes.

Cover cropping is an agricultural management practice that expands living plant cover over a larger portion of the year and adds diversity to crop rotations. In one common application of cover cropping, winter cereals are established in late fall, survive the winter, and grow in early spring before active termination with an 
herbicide in advance of spring cash crop planting (Kaspar and Singer 2011). This system of winter cover cropping eliminates the traditional winter fallow period and alters the timing of inputs of recently dead plant residue relative to the germination of a subsequent grain crop. Cover cropping has been shown previously to impact soil fungal communities (Nishizawa et al. 2010).

Microbial community dynamics on dead and dying plant tissues, such as those produced through cover cropping, may have functional implications. For instance, microbial activity drives the decomposition of crop residues, with impacts on the formation of soil organic matter and on nutrient availability to subsequent crops (Cotrufo et al. 2013). Furthermore, effects of cover crop residues on the phytobiome may influence rhizosphere development, beneficial microbial interactions, or disease epidemiology of a subsequent crop, because rhizosphere microbiome development is sensitive to characteristics of the initial pool of colonizing microbes (Bakker et al. 2015).

In crop production systems, impacts on the growth, reproduction and fate of plant pathogens are among the most important influences of crop residue. The conditions created by agricultural management with cover crops may provide opportunity for growth and proliferation by some plant pathogens. Bakker et al. (2016) demonstrated that two Fusarium species and two Pythium species that were pathogenic on corn seedlings were able to increase in density in the roots of herbicide-terminated rye cover crops. Thus, understanding microbial community dynamics on cover crop residues is vital to management decisions aimed at limiting disease risk.

Our primary objectives in this work were as follows. (i) Track the dynamics of oomycete and fungal communities in response to the death of cereal rye plants that had been grown as a winter cover crop in a field setting, and that were actively killed with herbicide. (ii) Relate characteristics of the oomycete and fungal communities associated with cover crops to variables such as time since herbicide application, spatial location across a field, or relevant soil edaphic properties. (iii) Investigate the potential for cover cropping to influence pathogen pressure on a subsequent corn crop using a method that avoids bias associated with ease of cultivation in the laboratory. Based on the community profiles obtained by amplicon sequencing, we isolated cultivation-resistant oomycete taxa associated with rye cover crop roots and assessed their pathogenicity on corn seedlings.

\section{MATERIALS AND METHODS}

Site description. A field experiment was conducted on an Iowa State University research farm in Boone County, IA $\left(42^{\circ} 1^{\prime} 15^{\prime \prime} \mathrm{N}\right.$, $\left.93^{\circ} 46^{\prime} 26^{\prime \prime} \mathrm{W}\right)$. The field used in this experiment was in a cornsoybean rotation system, with both phases of the rotation present each year, and had a history of no-till management since 1995.
The predominant soils series in the field are Clarion loam, Nicollet clay loam, and Webster silty clay loam, all formed from glacial till (Andrews and Diderikson 1981). Controlled traffic had been implemented since establishment; all machinery and foot traffic were restricted to the same interrows each year and row location was maintained from year to year. More detailed descriptions of the field have been reported previously (Parkin and Kaspar 2006). Air and soil temperatures, soil moisture content, and precipitation at the site (Table 1) were calculated using daily values from a weather station located less than $1 \mathrm{~km}$ from the field (Iowa Environmental Mesonet 2016).

In the fall of 2013, a cover crop of winter cereal rye (cultivar Elbon) was planted at a rate of $3.125 \times 10^{6}$ seeds $^{-1}$, by broadcast seeding and incorporation with a roller-chopper. The field was divided into five blocks, within which plots $(3.8 \mathrm{~m} \times 53 \mathrm{~m})$ were randomly assigned to an early or a late cover crop termination treatment. The following spring (2014), glyphosate $(\mathrm{N}-$ (phosphonomethyl) glycine; $0.66 \mathrm{~kg}$ of active ingredient ha ${ }^{-1}$ ) was applied on 22 April for plots assigned to the early termination treatment, or 5 May for plots assigned to the late termination treatment. The field was managed similarly in the subsequent 2 years.

To investigate relationships between soil properties and oomycete community composition, we collected soil samples from each plot for analysis of soil organic matter (OM) and sand content. These properties are closely related to soil moisture status, which is relevant to oomycete life history. From each plot, two subsamples consisting of three soil cores each $(3.2 \mathrm{~cm}$ diameter $\times 5 \mathrm{~cm}$ depth) were drawn from the interrow off the center row of the plot. To determine $\mathrm{OM}$, approximately $50 \mathrm{~g}$ of oven-dried soil from each subsample was used to determine weight loss on ignition with a programmable muffle furnace (Fisher-Scientific Isotemp $650-126$ ) at $460^{\circ} \mathrm{C}$ for $16 \mathrm{~h}$. The $\mathrm{OM}$ content was considered to be the ash-free change in weight after burning (Kaspar et al. 2006). Sand content was determined on the burned soil samples on a weight basis by dispersing the samples with $250 \mathrm{ml}$ of $5 \mathrm{~g} \mathrm{liter}^{-1}$ of sodium hexametaphosphate, shaking for no less than $18 \mathrm{~h}$, and then wet sieving through a $53-\mu \mathrm{m}$ sieve and weighing the dry sand remaining on the sieve (Cambardella et al. 2001).

Sample collection and processing. Rye roots were sampled from both treatments on each of three different dates: 25 April, 9 May, and 23 May 2014. To collect rye roots, a probe $(3.2 \mathrm{~cm}$ diameter) was centered over the crown of an individual rye plant and a soil core was collected to a $15 \mathrm{~cm}$ depth. At the first two sampling dates, a single core was collected per plot. At the last sampling date, three subsamples were collected per plot. Soil cores were transported to the lab on ice and were stored frozen until processing. Rye roots were collected on a screen while soil was washed away under a high pressure stream of water. Washed roots

TABLE 1

Weather data for the field plot from which roots of cereal rye cover crops were sampled in the spring of 2014

\begin{tabular}{lcrr}
\hline & $\begin{array}{c}\text { Mean air } \\
\text { temperature }\left({ }^{\circ} \mathrm{C}\right)\end{array}$ & $\begin{array}{c}\text { Mean soil temperature } \\
\left(10 \mathrm{~cm} \text { depth; }{ }^{\circ} \mathrm{C}\right)\end{array}$ & $\begin{array}{c}\text { Mean soil water content } \\
(30 \mathrm{~cm} \text { depth; \%) }\end{array}$ \\
\hline Month of: & & & $\begin{array}{c}\text { Precipitation } \\
(\mathrm{mm})\end{array}$ \\
\hline March & 0.4 & -0.2 & 20.8 \\
\hline April & 9.8 & 9.6 & 36.6 \\
\hline May & 16.6 & 23.8 & 38.7 \\
\hline Two weeks preceding sample collection on: & & & 120.7 \\
\hline 25 April & 11.2 & 11.2 & 36.8 \\
\hline 9 May & 13.1 & 15.1 & 38.1 \\
\hline 23 May & 14.9 & 19.8 & 34.3 \\
\hline
\end{tabular}


were freeze-dried and pulverized by beating with a tungsten-carbide bead (3 mm diameter; Qiagen) on a MiniBeadbeater (Biospec Products). DNA was extracted using the DNeasy Plant Mini Kit (Qiagen). Where multiple samples were collected per plot, DNA extracts were pooled to a single sample per plot.

Amplicon sequencing. For library preparation, DNA extracts were diluted $20 \times$ with molecular biology grade water before PCR amplifying the internal transcribed spacer (ITS) region of the rRNA gene for oomycetes, or the $18 \mathrm{~S}$ rRNA gene for fungi. For the oomycete ITS amplicon, we used the primer pair ITS6 (5'-GAA GGT GAA GTC GTA ACA AGG-3') and ITS7 (5'-AGC GTT CTT CAT CGA TGT GC-3') (Vannini et al. 2013) with appropriate 454 adaptors and a 10 nucleotide barcode in each of the forward and reverse primer constructs. The thermocycler program consisted of $8.5 \mathrm{~min}$ at $95^{\circ} \mathrm{C} ; 35$ cycles of $30 \mathrm{~s}$ at $95^{\circ} \mathrm{C}, 30 \mathrm{~s}$ at $59^{\circ} \mathrm{C}$, and $1 \mathrm{~min}$ at $72^{\circ} \mathrm{C}$; and $5 \mathrm{~min}$ at $72^{\circ} \mathrm{C}$. For the fungal $18 \mathrm{~S}$ rRNA amplicon, we used the primer pair nuSSU1196 (5' - GGA AAC TCA CCA GGT CCA GA- $3^{\prime}$ ) and nuSSU1536 (5'- ATT GCA ATG CYC TAT CCC CA-3') (Borneman and Hartin 2000) with appropriate 454 adaptors and a 10 nucleotide barcode on the forward primer only. The thermocycler program consisted of $8.5 \mathrm{~min}$ at $95^{\circ} \mathrm{C} ; 35$ cycles of $15 \mathrm{~s}$ at $95^{\circ} \mathrm{C}, 30 \mathrm{~s}$ at $58^{\circ} \mathrm{C}$, and $1 \mathrm{~min}$ at $72^{\circ} \mathrm{C}$; and $5 \mathrm{~min}$ at $72^{\circ} \mathrm{C}$. The Maxima SYBR Green master mix (ThermoFisher Scientific) was used for all reactions.

Amplified PCR products were purified using the FlashGel double tier electrophoresis system (Lonza Rockland, Inc.) and quantified using the Quant-iT PicoGreen dsDNA Assay Kit (Invitrogen). Six nanograms of DNA from each sample was combined to generate an oomycete and a fungal library for pyrosequencing. Libraries were purified and concentrated using Ampure Beads (Beckman Coulter) and quantified using the Library Quantification Kit (KAPA). Sequencing was performed on the Roche GS Jr. platform (454 Life Sciences). The raw data (.sff files) have been deposited at the NCBI Sequence Read Archive as experiment SRX1518163.

Oomycete data processing. For the oomycete dataset, ITSx version 1.0.11 (Bengtsson-Palme et al. 2013) was used to extract the ITS region from each read. It is important to constrain ITS amplicon sequencing data to just the ITS region (Lindahl et al. 2013), because differential representation of the very highly conserved flanking regions can influence sequence binning or other aspects of data processing. Amplicon sequences flagged by ITSx as likely belonging to taxa other than oomycetes were culled. We used custom scripting to trim quality scores in the corresponding file to include only those base calls that were retained by ITSx.

Additional processing of sequence data was performed with the software Mothur v. 1.38.0 (Schloss et al. 2009). We required a perfect match to the forward barcode sequence, and allowed 1 mismatch to the reverse barcode. Our dual-index strategy required culling any sequences that were not full length, because the $3^{\prime}$ barcode was required to assign sequences to their sample of origin. Sequences were trimmed where the average quality score in a sliding window fell below 25 , and were culled if they contained ambiguous base calls. Oomycete ITS reads passing these criteria were preclustered, binning together reads that differed in two or fewer positions. Chimeras were identified with UCHIME (Edgar et al. 2011), using both self and the classification database as references, and were culled.

We used distance based greedy clustering (Rognes et al. 2016; Westcott and Schloss 2015) to bin reads into operational taxonomic units (OTUs), at a distance threshold of 0.03. This method requires only pairwise alignments, which alleviates difficulties associated with aligning ITS sequences. Singleton OTUs were excluded from analysis. Classification of sequences used the naïve Bayesian classifier (Wang et al. 2007) implemented in Mothur, and a custom set of reference sequences with associated taxonomic information. This reference dataset consisted of the NCBI accessions generated in Table S1 of Robideau et al. (2011) and Table 19 of Hyde et al. (2014). Accessions from the two sources were merged and supplemented with an additional accession for $P$. volutum ATCC 58813. The ITS1 region was extracted using ITSx. Initial classifications of the dataset indicated a large number of reads likely belonging to a single taxon within Pythium clade B that did not have sufficient homology to any of the reference sequences to be classified. Three random sequences from this group were added to the reference database under the operational taxon name Pythium sp. F86, named for the field from which the original samples were drawn.

Fungal data processing. The fungal $18 \mathrm{~S}$ rRNA amplicon dataset was also processed in Mothur. Raw flow data were trimmed to 450 flows and were culled if there were homopolymeric runs longer than 10 nucleotides. Fungal sequences passing these criteria were denoised using the Mothur implementation of the PyroNoise algorithm (Quince et al. 2011). Denoised data were screened to permit no more than two mismatches to the forward primer, and to require a perfect match to the barcode sequence. It has been demonstrated using mock communities that primer mismatches can result from real biological variation (Gohl et al. 2016).

We used the SILVA small subunit reference NR 99 Release 128 database (Quast et al. 2013), extracting from the complete database only those reads belonging to fungi or to the plant order Poales (to which the host plant in our study belongs). Sequences were culled if they did not start by, or ended before, the position in the alignment by which $95 \%$ of sequences started and ended. Sequences that were unclassifiable or that were classified as of plant origin (21.8\% of raw reads) were removed. Chimeras were identified using both self and the classification database as references, and were culled. Sequences were binned into OTUs via distance based greedy clustering. The low distance threshold of 0.01 was used, due to the highly conserved nature of the fungal $18 \mathrm{~S}$ rRNA gene. Singleton OTUs were culled.

A record of commands used to process the raw sequence files into the final datasets is included as Supplementary Material S1.

$\boldsymbol{P}$. volutum infection of corn radicles. We performed follow up experiments to validate the presence of $P$. volutum at our field site, and to test the potential for $P$. volutum to impact corn seedlings planted following a rye cover crop.

In the spring of 2015, we assessed the density of $P$. volutum in the roots and mesocotyls of corn seedlings grown in the same field from which samples were drawn for amplicon sequencing the prior year. Corn seedlings were collected from plots in which they either followed a rye cover crop or followed a no cover crop control. Corn seedling radicle and mesocotyl tissue were collected by digging up six seedling plants at irregular intervals across each experimental plot $(n=5)$. For each plant, we collected the first $2 \mathrm{~cm}$ of radicle and $2 \mathrm{~cm}$ of mesocotyl extending away from the seed. Sections of radicle or of mesocotyl from three plants were bulked into a single DNA extraction, leaving two subsamples per plot. Roots and mesocotyls were washed and processed for DNA extraction as described above.

The abundance of $P$. volutum in each tissue sample was measured with quantitative PCR (qPCR) on a CFX96 instrument (Bio-Rad). The PCRs were performed in a $20 \mu$ l volume using QuantiTect SYBR Green (Qiagen), forward and reverse primers at $200 \mathrm{nM}$ final concentrations, and $5 \mu \mathrm{l}$ of template DNA. For our qPCR primers, we used oligos reported by Tambong et al. (2006) to be specific for $P$. volutum (vol201ex: 5'-AAT GTA GTT TAT TCT GTA TGC GCG-3'; vol203rc: 5'-GTC AGC ACT TCT CTC AAA CAC-3'). 
Both oligos bind within the ITS region and together amplify a fragment of approximately $400 \mathrm{bp}$. The thermocycler program consisted of $95^{\circ} \mathrm{C}$ for $15 \mathrm{~min}$; and 40 cycles of $95^{\circ} \mathrm{C}$ for $15 \mathrm{~s}, 60^{\circ} \mathrm{C}$ for $30 \mathrm{~s}$, and $72^{\circ} \mathrm{C}$ for $30 \mathrm{~s}$ (plate read); melt curve.

Each qPCR plate included no-template controls and a standard curve of synthesized DNA (sequence matching positions 1875 to 2282 of GenBank accession AY598686.2) spanning 6 orders of magnitude in template copy number. Technical triplicates were run for all samples and standards. Nondetects were assigned a small nonzero value, defined as half of the calculated DNA content at a cycle threshold of 40. Expressing pathogen DNA abundance relative to host DNA abundance minimizes error associated with variation in DNA extraction efficiency. To enable this, we also assessed corn tua4 gene density in each DNA extract, using the qPCR assay of Mideros et al. (2009) and a standard curve of known copy number derived from a synthesized template (positions 20 to 82 of GenBank accession X73980.1).

Pythium isolations and pathogenicity assays. In the spring of 2016, we isolated Pythium strains from cereal rye cover crop roots grown in the same field from which samples were drawn for amplicon sequencing and determination of $P$. volutum load in corn seedling roots over the previous 2 years. Symptomatic sections of live roots of cereal rye, showing discoloration or disease lesions, were washed extensively with running tap water, rinsed briefly in $0.6 \% \mathrm{NaOCl}$ followed by sterile water, and blotted dry on sterile paper towels. These surface-disinfested root pieces were placed underneath a growth medium to provide opportunity for physical selection against nonfilamentous organisms incapable of growing through the solid medium. Plates were incubated at $14^{\circ} \mathrm{C}$. $P$. volutum has been previously reported to be extremely sensitive to several common additives in oomycete-selective growth media (Chamswarng and Cook 1985; Kerns and Tredway 2008a). We confirmed this sensitivity with isolate $P$. volutum ATCC 58813 (data not shown). Accordingly, we used a modified isolation media consisting of corn meal agar $\left(17 \mathrm{~g} \mathrm{liter}^{-1}\right)$ amended with rifampicin $\left(5 \mathrm{mg} \mathrm{liter}{ }^{-1}\right)$ and nystatin $\left(8 \mathrm{mg} \mathrm{liter}^{-1}\right)$.

Marker gene sequence data were used to identify Pythium spp. isolated from rye roots. Marker gene sequences were obtained by PCR amplifying and Sanger sequencing the ITS region of the ribosomal RNA gene, and the cytochrome $\mathrm{C}$ oxidase subunit I (COI) gene, using the primers and method of Robideau et al. (2011).

Marker gene sequences of the closest relatives of $P$. volutum, as indicated by the five gene phylogeny of Hyde et al. (2014), were obtained from GenBank. A maximum likelihood phylogeny of our unknown isolates with their closest relatives was generated using the CLC Genomics Workbench (Qiagen). Briefly, sequences were trimmed to the same region and aligned. A phylogram was constructed using the neighbor-joining method and the Jukes-Cantor nucleotide substitution model.

Pathogenicity assays were performed using a known isolate of $P$. volutum (strain ATCC 58813), as well as strains of $P$. volutum and Pythium sp. F86 that were isolated in this work. To produce inoculum, equal volumes of sand and vermiculite (1,450 $\mathrm{g}$ total) were combined with $100 \mathrm{~g}$ of corn meal and $450 \mathrm{ml}$ of tap water in an autoclavable plastic bag with an air exchange patch. The substrate was autoclaved on a $30 \mathrm{~min}$ cycle on each of two consecutive days. The sterile substrate was infested with 10 pieces $\left(1 \mathrm{~cm}^{2}\right)$ of colonized agar, heat sealed, and incubated at $15^{\circ} \mathrm{C}$ for 18 days. After homogenization, this colonized medium was used directly as the potting medium for corn seedling growth. Inoculum strength was estimated by extracting DNA from a 7.5-g subsample of colonized substrate (FastDNA 50-ml SPIN kit, MP Biomedicals) and performing quantitative PCR using the same primers as were used for amplicon sequencing. Pathogen biomass was ranked and the two isolates having the lowest inoculum strength were dropped from the experiment. Estimated inoculum strength differed by threefold or less among the remaining pathogen isolates (four isolates of $P$. volutum, three isolates of Pythium sp. F86), and was not adjusted. The noninoculated control substrate showed no amplification.

Corn seeds of hybrid cultivar PO448 (Dupont Pioneer; no chemical treatment) were surface-disinfested by shaking for 2 min in $70 \%$ ethanol, and then $20 \mathrm{~min}$ in $0.6 \% \mathrm{NaOCl}$ plus detergent, and rinsed four times with sterile water. Seeds were pre-imbibed between sheets of moist filter paper for 1 day at room temperature. Two seeds were planted per pot $(3.8 \mathrm{~cm} \times 21 \mathrm{~cm}$; Stuewe \& Sons, Inc.), with 10 replicate pots per treatment (medium infested with a putative pathogen isolate, or noninfested medium). Pots were grown at a constant $14^{\circ} \mathrm{C}$ with $12 \mathrm{~h}$ days in a controlled environment chamber, in a randomized complete block design. Pots were watered three times a week with $15 \mathrm{ml}$ of deionized water or fertilizer solution (once only). At 21 days after planting, roots were washed and examined for disease symptoms, and radicle lengths were measured. For $P$. volutum ATCC 58813 only, roots were also processed for recovery of the pathogen on selective growth media. Isolates recollected from corn roots were compared morphologically and by marker gene sequence to confirm that the same isolate that was used in inoculation was recovered from the diseased tissue.

A note on sampling. The same field site was sampled at several different points in time across several years. Sampling location within plots was not precisely matched for samples destined for DNA extraction versus for isolations, versus for edaphic characterization.

Statistical analyses. One sample in the oomycete dataset had very low sequence yield, and was excluded from analysis. Sequences were randomly subsampled to the depth of the smallest sample (443 reads for the oomycete dataset, 405 reads for the fungal dataset) prior to estimating diversity and calculating community similarity indices, which formed the basis for both ordinations and statistical tests for differences in community structure. Patterns of similarity in microbial community structure were visualized via principal coordinates analysis ( $\mathrm{PCoA}$; function cmdscale in $\mathrm{R}$ ), using pairwise Bray-Curtis or weighted UniFrac distances (Lozupone et al. 2007) as the input data. The VEGAN package for $\mathrm{R}$ (Oksanen et al. 2016) was used to fit soil OM and sand content onto ordinations (envfit function). The significance of differences in community structure among treatments was assessed with analysis of molecular variance (AMOVA), as implemented in Mothur.

To test for differences in the mean proportional abundance of certain oomycete taxa (i.e., P. volutum and Pythium sp. F86 across experimental blocks, or $L$. radicicola per sampling time point), sequence reads were summed across OTUs assigned to the same taxon. The centered log-ratio transformation (Gloor and Reid 2016) was used to alleviate statistical difficulties associated with compositional data and to improve assumptions of homogeneity of variances. Transformed sequence abundance data, as well as OTU diversity index values, were subjected to analysis of variance (ANOVA) (additive models, incorporating the blocking factor plus the sampling date) with Tukey contrasts. We identified fungal taxa that either increased or decreased over time by ranking OTUs according to the slope of their proportional abundances across the three sampling dates.

In the pathogenicity assays, corn radicle lengths were averaged across the two plants per pot and analyzed by ANOVA (additive model, consisting of blocking factor and Pythium isolate) with Tukey contrasts. Measured $P$. volutum densities in corn tissue were expressed as the ratio of $P$. volutum ITS gene copy number to corn tua4 gene copy number, and then were $\log _{10}$ transformed. Transformed density ratios were analyzed by ANOVA (additive 
model, consisting of blocking factor and cover crop treatment) with Tukey contrasts.

\section{RESULTS}

Oomycete community membership and dynamics in the roots of a rye cover crop. Our final oomycete amplicon dataset consisted of 32,953 ITS sequence reads, across 230 OTUs. These OTUs could be further binned into a much smaller number of described taxa (Table 2). The vast majority of reads belonged to organisms from Pythium clade B: Pythium volutum comprised $47.3 \%$ of reads, and its close relative, Pythium sp. F86, comprised $40.4 \%$ of reads. L. radicicola made up $8.7 \%$ of reads, and the remaining $4 \%$ of reads were divided among several other Pythium and Globisporangium species, or could not be confidently assigned an identity (Table 2).

Irrespective of termination timing or sampling date, oomycete communities were strongly structured by spatial position of sample origin within the field (Fig. 1; experimental blocks arranged 1 to 5, west to east). This effect was predominantly the result of a switch in the dominant Pythium species from west to east across the field; $P$. volutum dominated the oomycete community in the western half of the field, while Pythium sp. F86 dominated the oomycete community in the eastern half of the field (Fig. 2A). Sampling date was also a significant factor for $P$. volutum relative abundance $(P=$ $0.002)$, but was not for Pythium sp. F86 $(P=0.11)$. The relative abundance of $P$. volutum increased significantly (ANOVA, $P<$ $0.05)$ between the first sampling date $(32.8 \%$ of reads) and the later sampling dates (46.2 and $50.1 \%$ of reads at the second and third sampling dates, respectively).

Likely explanations for the switching of dominant Pythium species across the field site may be associated with soil properties and elevation differences. Soil sand content was significantly related to oomycete community structure (by permutation test, $P=$ 0.002 for the fit of sand content onto an ordination based on oomycete community structure; Fig. 1). Organic matter was not significantly related to oomycete community structure $(P=0.18)$. There is an elevation change of approximately $3 \mathrm{~m}$ over the field site and a change in slope gradient and direction (Supplementary
Material S2), which is consistent with the change in dominant Pythium species. The western portions of the field, where $P$. volutum dominates, have slightly higher elevation, but lower soil sand content and impeded water shedding due to variable direction of slope. The eastern portions of the field, where Pythium sp. F86 dominates, have slightly lower elevation, but higher sand content and long slopes of consistent orientation that would facilitate water movement. In sum, the abundances of the two most prevalent oomycete taxa were most strongly related to spatial location in the field.

In contrast, the third most abundant oomycete taxon, $L$. radicicola, responded dramatically to host plant death; for both early and late termination treatments, the relative abundance of $L$. radicicola dropped quickly with time after herbicide application. In both the early and late termination treatments, $L$. radicicola had been significantly reduced in abundance between the first and the last sampling date (Fig. 2B).

Quantitative PCR and isolation of Pythium species. In the field, $P$. volutum was not detectable by $\mathrm{qPCR}$ in corn seedlings grown following a winter fallow, but was readily detectible in radicles and mesocotyls of corn seedlings grown following a cereal rye cover crop (Fig. 3A). In the fallow control, no corn tissue samples showed amplification with $P$. volutum primers. In contrast, primers selective for $P$. volutum amplified a product in $80 \%$ (early termination treatment) to $100 \%$ (late termination) of corn radicles, and $60 \%$ (late termination) to $80 \%$ (early termination) of corn mesocotyls following a rye cover crop. Measured $P$. volutum densities in corn radicles were significantly higher than the control for both termination treatments, and densities in corn mesocotyls were significantly higher than the control for the early cover crop termination treatment (Fig. 3A; ANOVA, $P<0.05$ ). Thus, the ability of cereal rye to host $P$. volutum also results in higher loads of this pathogen in corn seedlings following a cereal rye cover crop.

To validate the dominant Pythium species as indicated by our amplicon sequencing and qPCR data, we successfully isolated strains of $P$. volutum and of Pythium sp. F86 from roots of rye cover crops in the field. Identification of these strains was confirmed by marker gene sequencing. We have deposited COI and ITS sequences for $P$. volutum ATCC 58813, and for isolates of $P$. volutum

TABLE 2

Oomycete species detected in roots of a cereal rye cover crop via amplicon sequencing

\begin{tabular}{|c|c|c|c|c|}
\hline Genus & Clade & Species & Mean abundance (\% of reads) & Number of OTUs \\
\hline Globisporangium & $E$ & acrogynum & $<0.1$ & 1 \\
\hline Globisporangium & $\mathrm{F}$ & attrantheridium & 0.3 & 1 \\
\hline Globisporangium & $\mathrm{F}$ & recalcitrans & 0.3 & 6 \\
\hline Globisporangium & J & perplexum & $<0.1$ & 1 \\
\hline Pythium & A & monospermum & $<0.1$ & 3 \\
\hline Pythium & $B$ & aristosporum/arrhenomanes ${ }^{a}$ & 0.2 & 2 \\
\hline Pythium & B & sp. F86 & 40.4 & 71 \\
\hline Pythium & B & volutum & 47.3 & 48 \\
\hline Unclassified oomycetes & & Unclassified & $<0.1$ & 2 \\
\hline
\end{tabular}

a These two described species cannot be distinguished on the basis of internal transcribed spacer (ITS) marker gene sequence. 
and Pythium sp. F86 collected in this work as GenBank accessions KX266866 to KX266871.

A maximum likelihood phylogeny of ITS gene sequences for P. volutum and Pythium sp. F86, along with their 11 closest relatives (Fig. 4), yielded a topology consistent with the more extensive five gene phylogeny of Hyde et al. (2014). Our P. volutum isolates grouped together with prior collections of this species. However, our isolates of Pythium sp. F86 did not cluster with any other species, indicating that this is likely an undescribed species.

The COI gene has been proposed as a useful marker for nonphylogenetic identification of Pythium species (Robideau et al. 2011). While this gene does not provide congruent phylogenetic trees compared with several other genes (Hyde et al. 2014), measures of sequence similarity can still be helpful in determining the taxonomic placement of novel isolates. Our isolates of $P$. volutum had a COI sequence that was $>99 \%$ similar to other $P$. volutum isolates, which supports our identification of this species. In contrast, Pythium sp. F86 had a COI sequence that was only 92.4 to $94.0 \%$ similar to any of its 12 closest relatives. This further suggests that Pythium sp. F86 is likely an undescribed species.

Corn seedlings grown in a medium that had been infested with P. volutum or Pythium sp. F86 showed reduced rates of emergence, as well as visible symptoms of root disease. In particular, corn radicles uniformly failed to elongate, presumably due to the death of the radicle tip (Fig. 3). Corn seedlings grown in noninfested growth medium under the same conditions showed normal radicle development and elongation. $P$. volutum isolates sharing an identical marker gene sequence to the inoculated strain were recovered from necrotic radicle tips, as well as from asymptomatic seminal roots of plants grown in an infested medium (data not shown). Corn seedlings grown in infested medium sometimes also failed to properly elongate their first leaves, a symptom which has previously been reported on wheat in response to $P$. volutum infection (Chamswarng and Cook 1985). Pythium sp. F86 appears to be a somewhat less aggressive pathogen than $P$. volutum, allowing some radicle growth before tip necrosis and having less dramatic impacts on emergence (Fig. 3; considering isolates as reps, T-test on corn radicle length for $P$. volutum versus Pythium sp. F86; $P=$ $0.0039)$. In sum, these pathogenicity assays indicate that $P$. volutum and Pythium sp. F86, the dominant oomycetes in roots of a rye cover crop, are capable root rot pathogens of corn seedlings.

Fungal community membership and dynamics in the roots of a rye cover crop. Our final fungal $18 \mathrm{~S}$ rRNA gene dataset consisted of 56,783 reads, which were binned into 837 OTUs. The dataset was divided across the Ascomycota (76.3\% of sequence reads), Basidiomycota (22.8\%), Chytridiomycota (0.7\%), Glomeromycota $(0.1 \%)$, and Mucoromycotina $(0.01 \%)$, with the remainder of reads not confidently classified. Even after standardizing sampling effort by subsampling to the number of reads in the smallest sample (405 reads), estimated coverage of fungal taxa present in rye roots remained at least $90 \%$ for every sample. This indicates that sequencing more deeply would have revealed relatively few additional taxa.

The fungal community in roots of cereal rye grown as a winter cover crop and actively terminated with herbicide went through a successional process over time (Fig. 5A). Significant fungal community change occurred between each sampling date (AMOVA, $P \leq 0.007)$. At the coarsest taxonomic resolution, change over time

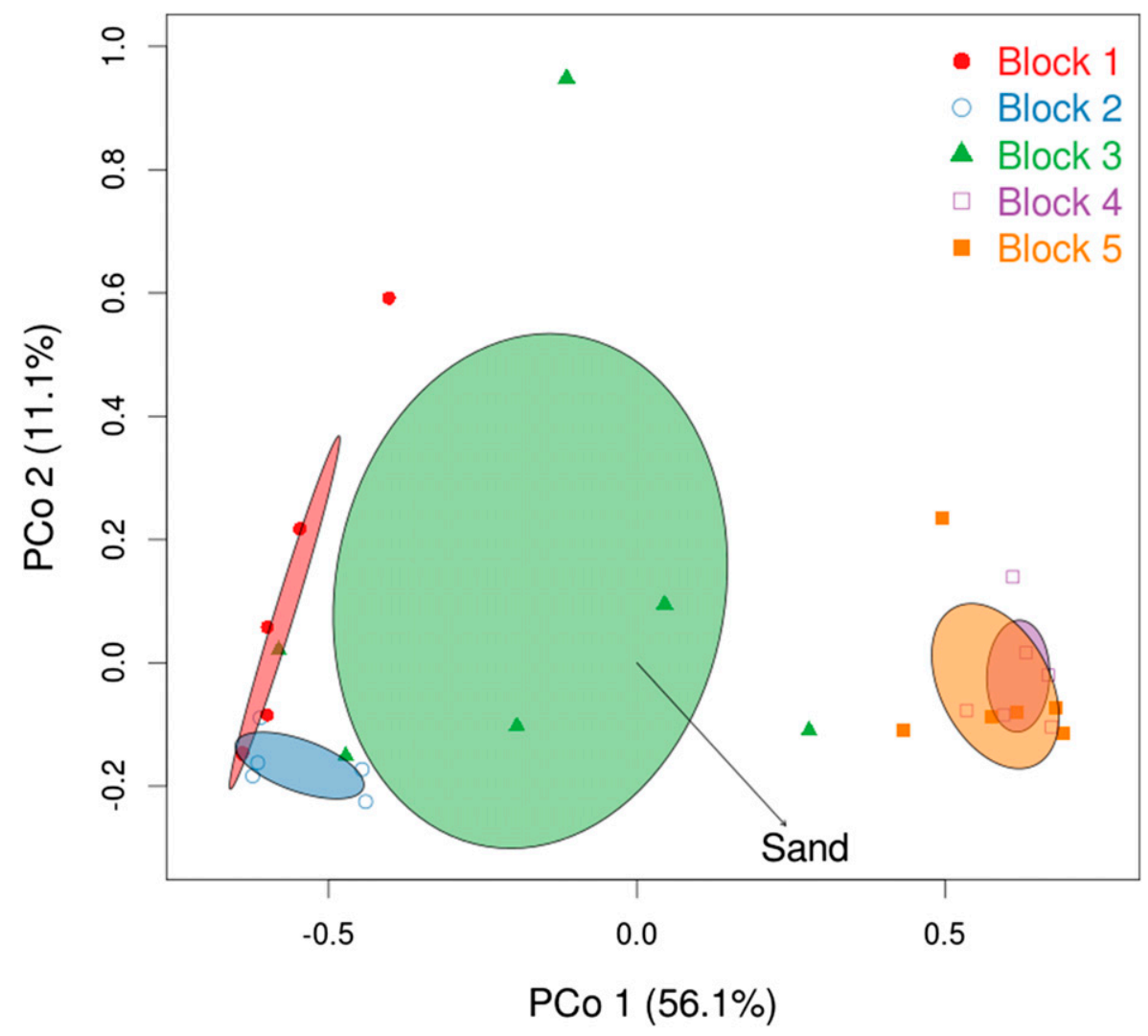

Fig. 1. A visualization of patterns of similarity in oomycete community structure among samples of cereal rye roots via principal coordinates analysis on Bray-Curtis dissimilarities. Shaded $95 \%$ confidence ellipses for the centroid of each group are shown. The axis labels indicate the proportion of the variation explained by each axis. The vector showing correlation of soil sand content was fit onto the ordination via the envfit function in the VEGAN package for $R$. 
was related to the displacement of basidiomycetes by ascomycetes (Fig. 5B). The fungal taxa whose relative abundance increased the most over time were OTU0001 (unclassified within Hypocreales), OTU0013 (Atractospora), OTU0007 (unclassified within Dothidiomycetes), OTU0023 (Bisporella), and OTU0018 (unclassified with Sordariomycetes). The fungal taxa whose relative abundance decreased the most over time were OTU0003 (Mrakia), OTU0004 (unclassified within Agaricomycetes), OTU0008 (unclassified within Tremallales), OTU0006 (unclassified within Pleosporales), and OTU0009 (Bisporella). It is notable that distinct OTUs with the same genus (Bisporella) responded oppositely over time. This highlights the potential for wide variation in phenotype or ecological role within narrowly defined microbial taxa, which poses a substantial challenge to drawing inferences from community survey data.

The observed number of fungal OTUs ranged from 22 to 71 per sample, after equalizing sampling depth. Phylogenetic diversity ranged from 0.69 to 2.78 , Hill's diversity index values ranged from 2.7 to 26.1, and Shannon's evenness index values ranged from 0.32 to 0.77 . However, these measures of fungal richness, evenness, and diversity did not differ significantly between sampling time points (ANOVA; $P>0.05$ ).

Five fungal OTUs were detected in every plot that was sampled, indicating that these were the most universally present fungi on or in roots of rye cover crops at our field site. Of these, two could be confidently classified to genus (Mrakia spp., and Tetracladium spp.). Mrakia is a basidiomycetous yeast known for being adapted to growth at cold temperatures (Tsuji et al. 2015), while Tetracladium has been characterized as a root endophyte (Sati et al. 2009). The remaining universally present OTUs could not be assigned with confidence to finely resolved taxonomic ranks, but all belonged to Pezizomycotina (Ascomycota).

Sixty-seven of the observed OTUs could be confidently identified to the genus rank (Supplementary Material S3). Several plant pathogens were included among these, including Aspergillus, Cochliobolus, and Verticillium. Other genera of interest, such as Sarocladium, have been categorized at times as plant pathogens, and at other times as nonpathogenic, beneficial endophytes (Giraldo et al. 2015). Potential pathogen antagonists were also detected. For instance, Cryptococcus has been evaluated for potential as a biocontrol agent to protect against plant disease (Schisler et al. 2015).

\section{DISCUSSION}

This work improves our understanding of how phytobiomes adjust to host plant death. Because plant death represents a switch in selective pressures acting on the phytobiome, this can be thought of as an instance of the more general process of community change in

\section{A Switching dominant Pythium species across the field}
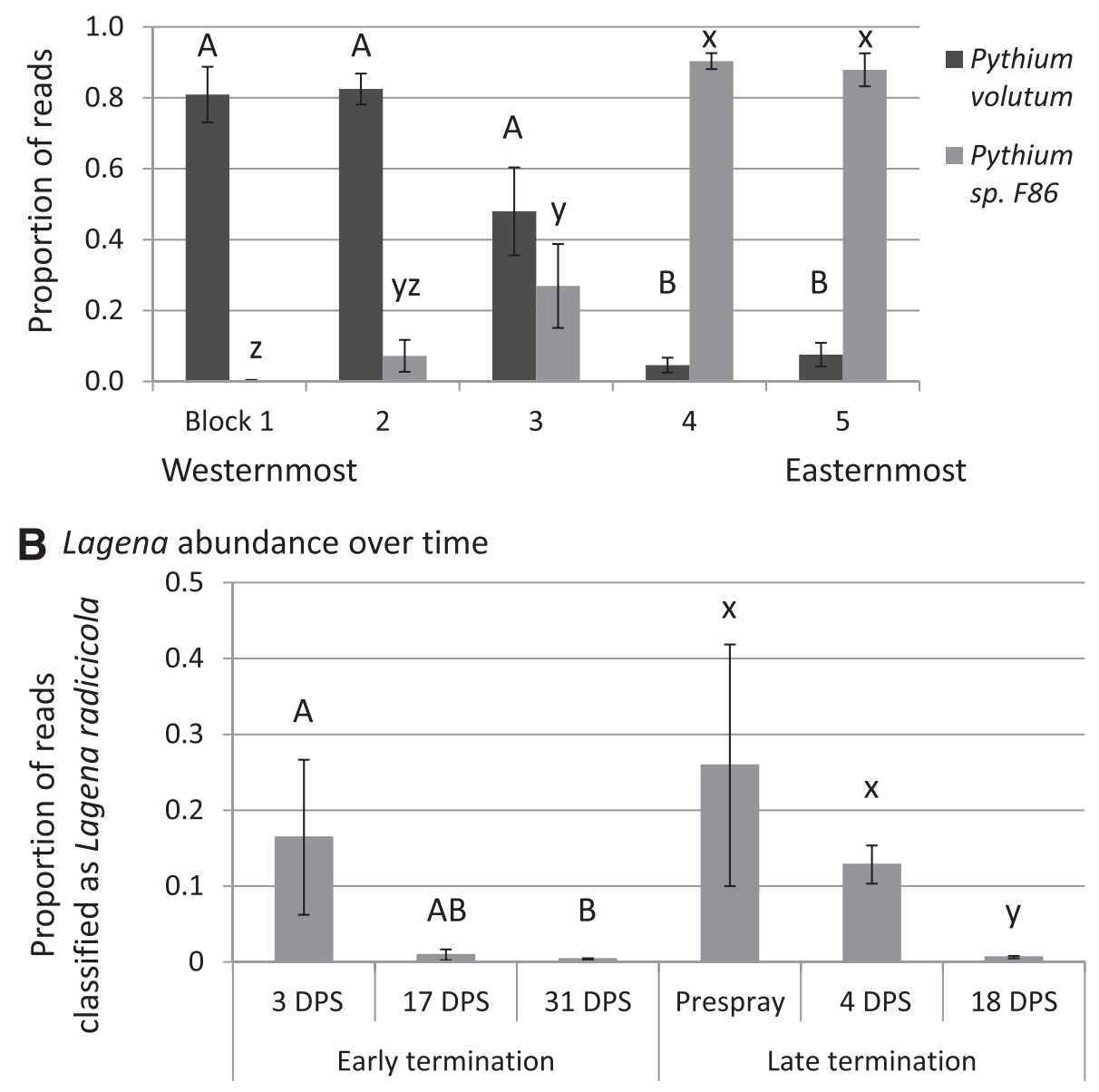

Fig. 2. A, Relative abundance of each of the two most abundant oomycete species by experimental block. The experiment is blocked from west to east across the field. B, Relative abundance of Lagena radicicola within oomycete communities in rye roots, as a function of the interval of time since herbicide application. DPS = days post spraying of herbicide to kill the cereal rye cover crop. In each panel, bars topped by the same letter do not differ significantly (analysis of variance with Tukey contrasts; $P>0.05$ ). While raw proportions are presented, statistical analyses were performed on centered log-ratio transformed data. 
response to perturbation. There have been several reports of microbial community change over time in plant roots and in the rhizosphere (Cotta et al. 2013; DeAngelis et al. 2009; Sugiyama et al. 2014), but as far as we are aware, this is the first study to report high-resolution microbial community structure over a time series in senescent roots. From an agronomic perspective, this work informs the more practical questions of how plant pathogens respond to plant death and how pathogen communities vary across space.

We hypothesized that oomycete and fungal communities would go through a period of rapid dynamics on their dying host plants as the rye cover crop was actively killed with herbicide. Certain pathogens may be able to grow rapidly on dying host plants (Bakker et al. 2016), due to compromised host defenses and increased resource availability. For instance, tilling in green cover crop shoot material has been shown to elevate Pythium population densities in some cases (Manici et al. 2004). However, pathogens should eventually be displaced from plant litter by more competitive saprotrophs. Yu and colleagues (2012) contrasted fungal communities in roots of Pisum sativum at vegetative, flowering, and senescent stages. They observed that mycorrhizal fungi and some putative pathogens declined in relative abundance in senescent roots, while putative saprotrophs increased in abundance. In the present study, L. radicicola served as a model of this process. L. radicicola is believed to be an obligate biotroph (Barr and Desaulniers 1990; Vanterpool and Ledingham 1930), and declined precipitously in abundance within several weeks of herbicide application to the cereal rye cover crop. However, other pathogens, such as $P$. volutum, did not demonstrate the same decline in abundance with host plant death. It is possible that relative abundance among sequence reads does not relate cleanly to the level of

A

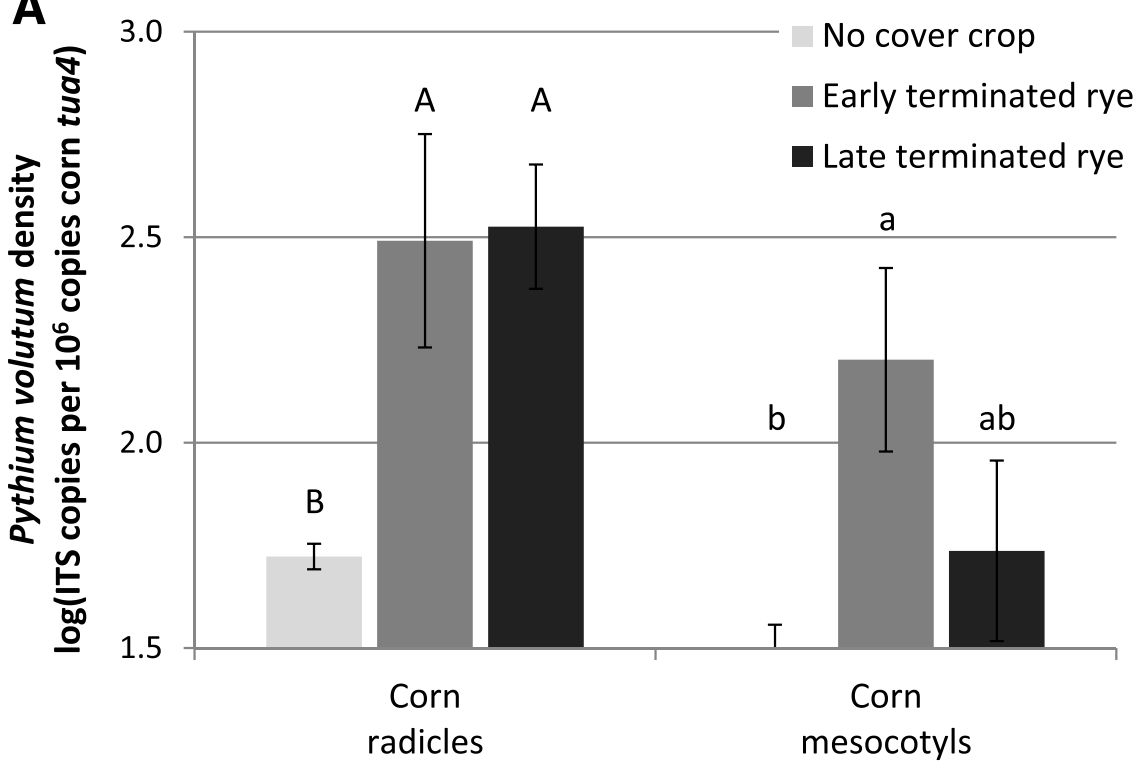

B Emergence rate:
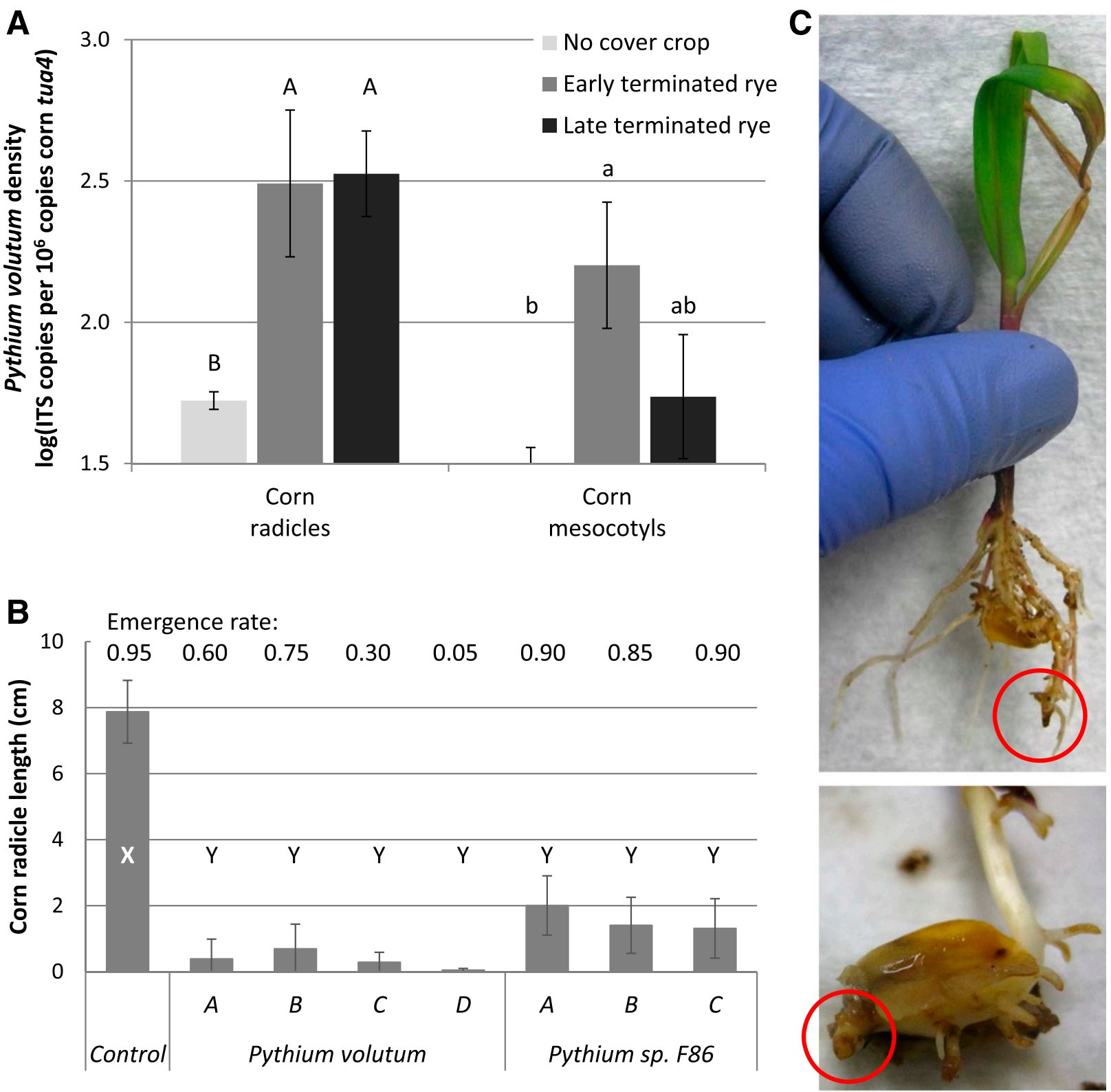

Fig. 3. A, Pythium volutum density in corn seedlings grown in the field $(n=5)$. B, Corn radicle length at 21 days after planting in a Pythium-infested medium or a noninfested control. Four isolates of $P$. volutum and three isolates of Pythium sp. F86 were tested. Values above the bars indicate emergence rates ( $n=10$ pots, with two seeds planted to each). C, Representative symptoms on corn seedlings after growing in a medium infested with $P$. volutum. Note the stunted radicles with necrotic tips (circled) and the improper leaf elongation. In each panel, bars topped with the same letter do not differ significantly (analysis of variance with Tukey contrasts; $P>0.05$ ). 
active biomass (Amend et al. 2010; Egge et al. 2013). For instance, much of the Pythium DNA present in our extracts may have originated from spores or survival structures. Some pathogens may also be competent saprotrophs, able to survive quite well after host plant death (Bakker et al. 2016).

Fungal biomass, richness and diversity have been previously reported to increase in senescent roots or in the rhizosphere of senescent plants, compared with earlier developmental stages of live plants (Hannula et al. 2012; Lee et al. 2011). While our data did not indicate a significant increase in fungal diversity as plant roots died, this may have been a function of our use of a marker (the 18S ribosomal RNA gene) with fairly limited power to resolve fungal taxa (Schoch et al. 2012). Because multiple described taxa may share an identical 18S rRNA gene sequence, many of the fungal OTUs described here may represent mixtures of distinct species. Thus, our method likely under-reports fungal diversity. There are always tradeoffs involved in choosing a marker gene, as the performance of candidate marker genes for delimiting taxa differs among taxa (e.g., see Table 1 in Hyde et al. 2014). The inability to confidently identify the organism of origin for many sequence reads also limits the ability to resolve fungal community change. Such inability to classify reads may be due to a lack of homologous sequence in the reference database, or to closely matching sequences in the reference database originating from multiple different taxa.

Early termination of the rye cover crop was expected to provide cooler and wetter conditions during the sampling period, while late termination was expected to provide warmer and drier conditions. We anticipated that these differences could impact microbial community dynamics and that testing both conditions might provide an indication of the variability of community dynamics in response to host plant death. The timing of termination also impacted rye growth stage and the total biomass produced, with the late terminated rye beginning to enter reproductive phase and accumulating substantially more biomass (data not shown). We did not include a treatment in which rye plants were sampled over time in the absence of herbicide application. Thus, we cannot state how stable fungal community structure may have been prior to or in the absence of herbicide application, or how responsive fungal communities may have been to temperature or moisture conditions rather than to host death per se. Any time series in this system (winter cereal rye grown under field conditions and sampled in the spring) would face the issue of confounding time with soil temperature and moisture conditions, and with changes in host plant physiology as the rye enters its reproductive phase. An additional potential source of confounding is the increase in the number of subsamples collected on the third sampling date. While pooling three subsamples per plot on this date likely helped to generate a more accurate plot-level "average" community profile, the decision to increase subsampling may have influenced observed community composition and structure compared with the single subsamples drawn on the first two sampling dates.

One of the striking findings of this work was the indication of the very strong spatial structuring of oomycete communities, while fungal communities showed greater responsiveness to time and to host plant death. Pythium species lack the ability for aerial dispersal possessed by many fungi, and this characteristic would contribute to spatial structuring of Pythium populations. Our field site also had a long history of management exclusively without tillage. All field operations are carried out in an orientation perpendicular to the spatial gradient in oomycete community structure. That is, oomycete communities change along an east-west gradient, while farm equipment is always operated in a north-south orientation in this field. Thus, the particular history and management of the agricultural field studied here is likely to have encouraged spatial structuring of Pythium populations by providing very few opportunities for mixing of populations from west to east. The westernmost end of the field has the highest elevation, less slope gradient, shorter slope length, the highest organic matter content and the lowest sand content. However, there is not a clean gradient of sand or OM content across the field. Historical contingency may have been an important factor, as the westernmost portion of the field (block 1) was under different management from the rest of the field at some time greater than 20 years ago.

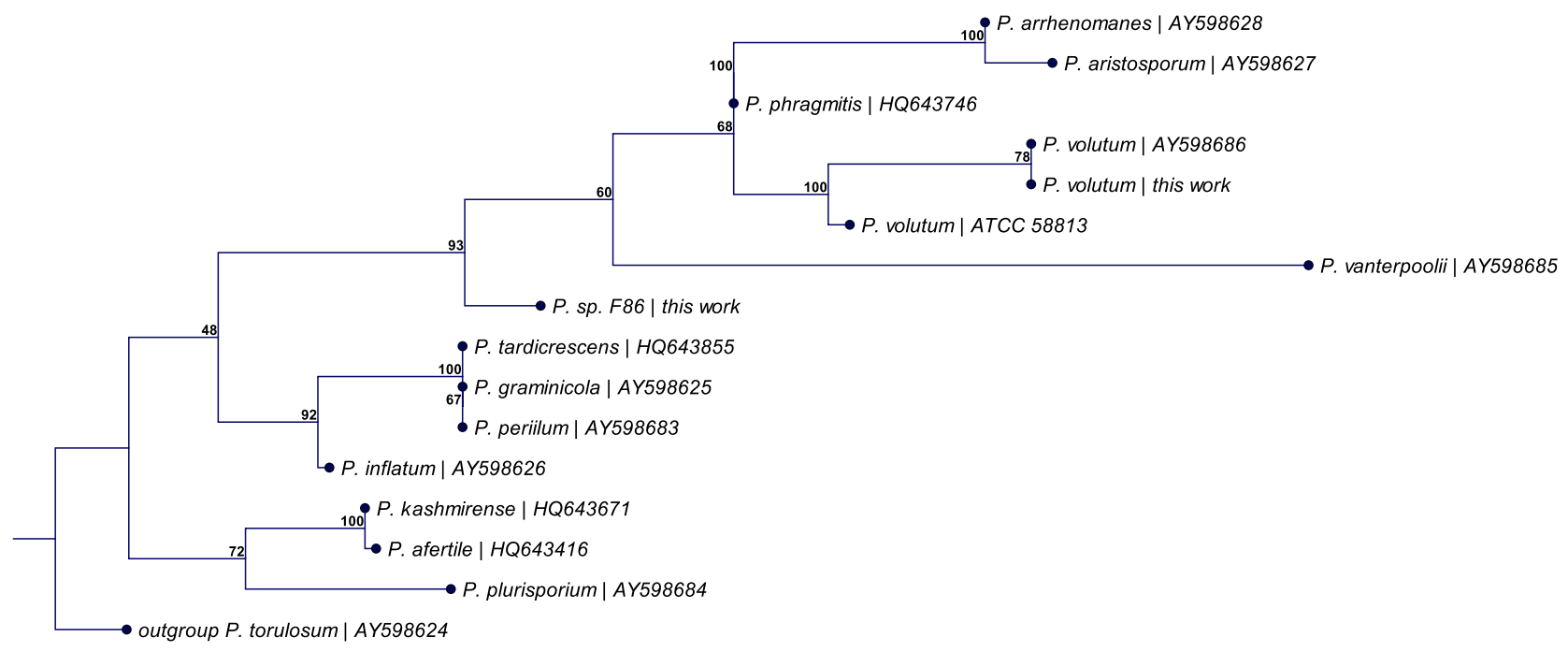

0.060

Fig. 4. Maximum likelihood phylogeny showing the placement of our Pythium volutum and Pythium sp. F86 isolates among their closest relatives. The phylogram is based on internal transcribed spacer sequence data, using the Jukes-Cantor nucleotide substitution model and the neighbor-joining construction method. Node labels indicate bootstrap support. GenBank accession numbers are provided in the branch tip labels. 
Similar to our findings in rye roots, a previous amplicon sequencing approach to identify oomycetes associated with carrots revealed relatively simple communities dominated by few taxa (Sapkota and Nicolaisen 2015). It was not expected that $P$. volutum would be recovered from our field site, particularly as the dominant member of the oomycete community. None of the several Pythium experts and plant disease diagnosticians from around the Upper Midwest that we consulted were familiar with this species. However, the species was originally described as a pathogen of cereals on the Canadian plains (Vanterpool and Truscott 1932) and has also been reported on small grains in the Pacific Northwest (Chamswarng and Cook 1985) and in Japan (Ichitani et al. 1986). More recently,
$P$. volutum has received attention as a pathogen of turf grass (Kerns et al. 2009; Kerns and Tredway 2008b). A key reason for the limited data on $P$. volutum may be that it is extremely sensitive to several chemicals used in the most common semiselective media for oomycetes (data not shown; see also Chamswarng and Cook 1985; Kerns and Tredway 2008a). Thus it seems likely that this species has been largely overlooked because of a bias inherent in traditional cultivation approaches for Pythium species.

Pythium sp. F86 represents an apparent novel, undescribed taxon closely related to $P$. volutum. Although we do not have the taxonomic expertise necessary for description of novel Pythium species, we were able to collect Pythium sp. F86 isolates from rye roots.

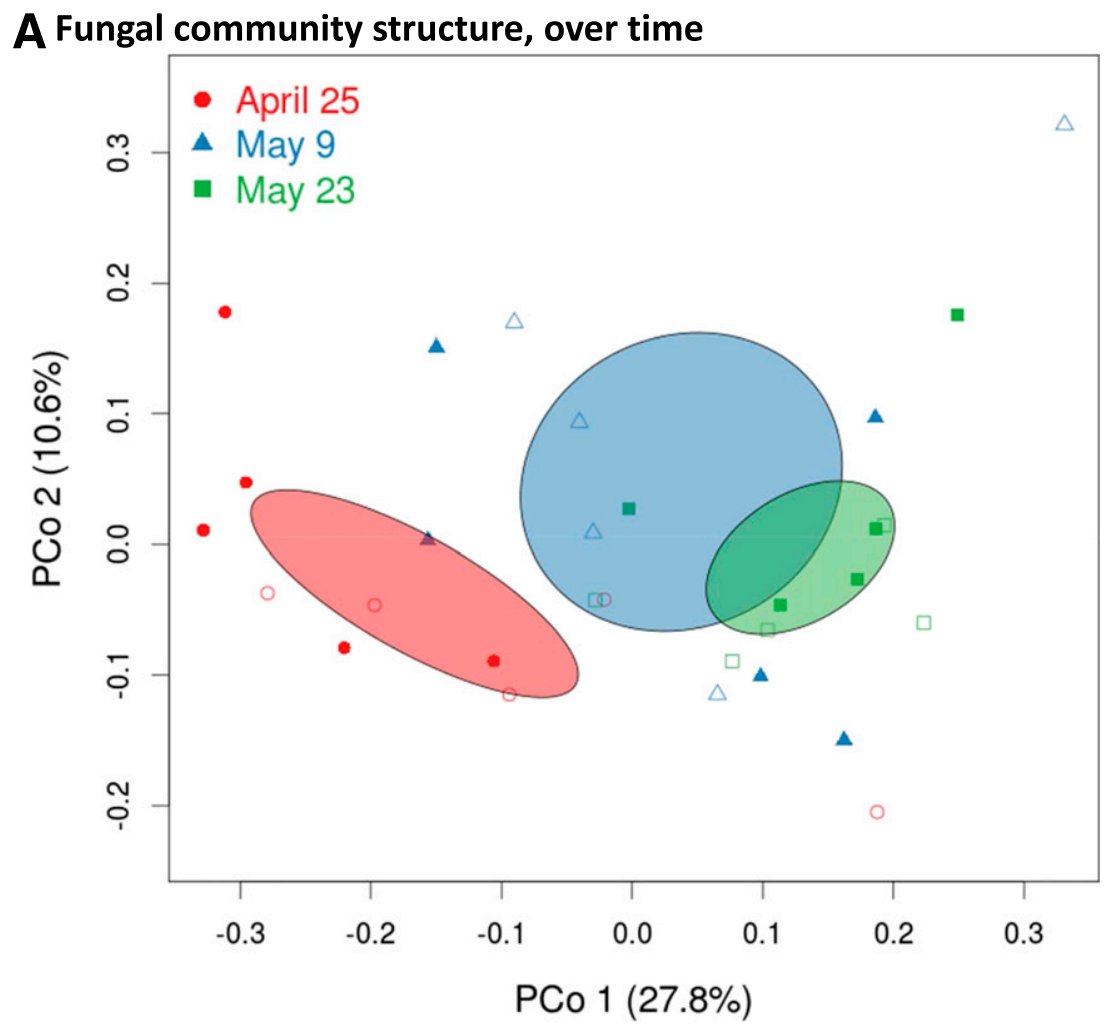

B Phylum level relative abundances

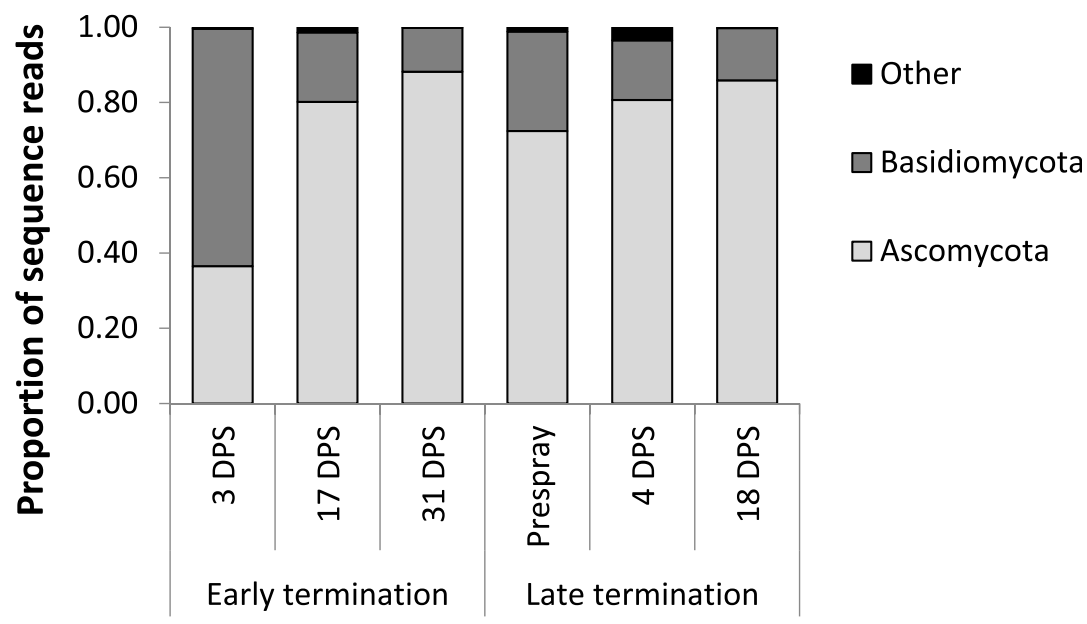

Fig. 5. A, Principal coordinates analysis plot for the visualization of patterns of similarity in fungal community structure (weighted UniFrac distance) among samples of cereal rye roots. Points are colored by sampling date. Filled symbols represent samples from the early termination treatment, while open symbols represent samples from the late termination treatment. Shaded 95\% confidence ellipses for the centroid of each group are shown. The axis labels indicate the proportion of the variation explained by each axis. B, The relative abundance of fungal phyla in cereal rye roots, at different intervals since the application of herbicide. DPS = days post spraying of herbicide. 
These isolates have ITS and COI marker gene sequences that suggest that they are part of a currently undescribed lineage. Thus, based on first detection in an amplicon sequencing survey, we were able to isolate a probable new species of Pythium.

$L$. radicicola, another of the most abundant oomycetes in our study, is even less amenable to cultivation, as it is believed to be an obligate intercellular parasite of plant roots (Barr and Desaulniers 1990; Vanterpool and Ledingham 1930). L. radicicola has been reported as very commonly causing stunting of root tips in the small grains, but to date has required microscopic examination of roots for diagnosis (Macfarlane 1970). By adopting an amplicon sequencing approach, our work revealed dominant members of the oomycete community that would likely have been missed entirely by standard cultivation techniques. Notably, a recent study from New Zealand also identified both $P$. volutum and $L$. radicicola in sequences of amplified oomycete DNA extracted from environmental samples (Dickie et al. 2016), which lends further support to the notion that these species may be of underappreciated importance because of their recalcitrance toward cultivation.

$L$. radicicola has been reported to be a pathogen on corn (Vanterpool and Ledingham 1930), and we demonstrate here that $P$. volutum and Pythium sp. F86 are able to cause disease on corn. Thus, the influence of cereal rye cover crops on oomycete communities may serve to expand populations capable of causing disease on the subsequent corn crop (Bakker et al. 2016).

In conclusion, a high throughput sequencing survey of fungal and oomycete communities associated with dying cereal rye cover crops revealed differences in the forces structuring oomycete versus fungal communities. The dominant oomycete taxa in this system are not readily cultured. However, guided by the amplicon sequencing survey, we were able to isolate the dominant Pythium species associated with cereal rye cover crop, and to demonstrate their pathogenicity on corn. Future work should explore whether these organisms are also abundant in other systems and what their contribution may be to corn seedling disease.

\section{ACKNOWLEDGMENTS}

We thank K. Kohler for managing the field trial sampled in this work and A. Robertson for providing advice that proved helpful in isolating $P$. volutum and for performing the pathogenicity test. Partial funding for this research was provided by the Leopold Center for Sustainable Agriculture (award E2012-03) and by the Iowa Nutrient Research Center.

\section{LITERATURE CITED}

Amend, A. S., Seifert, K. A., and Bruns, T. D. 2010. Quantifying microbial communities with 454 pyrosequencing: Does read abundance count? Mol. Ecol. 19:5555-5565.

Andrews, W. F., and Diderikson, R. O. 1981. Soil survey of Boone County, Iowa. USDA-SCS U.S. Gov. Print. Office, Washington, DC.

Bai, Y., Mueller, D. B., Srinivas, G., Garrido-Oter, R., Potthoff, E., Rott, M., Dombrowski, N., Muench, P. C., Spaepen, S., Remus-Emsermann, M., Huettel, B., McHardy, A. C., Vorholt, J. A., and Schulze-Lefert, P. 2015. Functional overlap of the Arabidopsis leaf and root microbiota. Nature 528:364-369.

Bakker, M. G., Glover, J. D., Mai, J. G., and Kinkel, L. L. 2010. Plant community effects on the diversity and pathogen suppressive activity of soil streptomycetes. Appl. Soil Ecol. 46:35-42.

Bakker, M. G., Manter, D. K., Sheflin, A. M., Weir, T. L., and Vivanco, J. M. 2012. Harnessing the rhizosphere microbiome through plant breeding and agricultural management. Plant Soil 360:1-13.

Bakker, M. G., Chaparro, J. M., Manter, D. K., and Vivanco, J. M. 2015. Impacts of bulk soil microbial community structure on rhizosphere microbiomes of Zea mays. Plant Soil 392:115-126.

Bakker, M. G., Acharya, J., Moorman, T. B., Robertson, A. E., and Kaspar, T. C. 2016. The potential for cereal rye cover crops to host corn seedling pathogens. Phytopathology 106:591-601.
Barr, D. J. S., and Desaulniers, N. L. 1990. The life cycle of Lagena radicicola, an oomycetous parasite of wheat roots. Can. J. Bot. 68:813-824.

Bengtsson-Palme, J., Ryberg, M., Hartmann, M., Branco, S., Wang, Z., Godhe, A., De Wit, P., Sanchez-Garcia, M., Ebersberger, I., de Sousa, F., Amend, A. S., Jumpponen, A., Unterseher, M., Kristiansson, E., Abarenkov, K., Bertrand, Y. J. K., Sanli, K., Eriksson, K. M., Vik, U., Veldre, V., and Nilsson, R. H. 2013. Improved software detection and extraction of ITS1 and ITS2 from ribosomal ITS sequences of fungi and other eukaryotes for analysis of environmental sequencing data. Methods Ecol. Evol. 4: 914-919.

Borneman, J., and Hartin, R. J. 2000. PCR primers that amplify fungal rRNA genes from environmental samples. Appl. Environ. Microbiol. 66:43564360 .

Cambardella, C. A., Gadja, A. M., Doran, J. W., Wienhold, B. J., and Kettler, T. A. 2001. Estimation of particulate and total organic matter by weight losson-ignition. Pages 349-359 in: Assessment Methods for Soil Carbon. R. Lal, J. M. Kimble, R. J. Follett, and B. A. Stewart, eds. CRC Press, Boca Raton, FL.

Chamswarng, C., and Cook, R. J. 1985. Identification and comparative pathogenicity of Pythium species from wheat roots and wheat field soils in the Pacific Northwest. Phytopathology 75:821-827.

Cotrufo, M. F., Wallenstein, M. D., Boot, C. M., Denef, K., and Paul, E. 2013. The microbial efficiency-matrix stabilization (MEMS) framework integrates plant litter decomposition with soil organic matter stabilization: Do labile plant inputs form stable soil organic matter? Glob. Change Biol. 19:988-995.

Cotta, S. R., Franco Dias, A. C., Marriel, I. E., Gomes, E. A., van Elsas, J. D., and Seldin, L. 2013. Temporal dynamics of microbial communities in the rhizosphere of two genetically modified (GM) maize hybrids in tropical agrosystems. Antonie Van Leeuwenhoek Int. J. Gen. Mol. Microbiol. 103: 589-601.

DeAngelis, K. M., Brodie, E. L., DeSantis, T. Z., Andersen, G. L., Lindow, S. E., and Firestone, M. K. 2009. Selective progressive response of soil microbial community to wild oat roots. ISME J. 3:168-178.

Dickie, I. A., Wakelin, A., Martinez-Garcia, L., Richardson, S. J., Makiola, A., and Tylianakis, J. M. 2016. Plant root pathogens over 120,000 years of temperate rainforest ecosystem development. bioRxiv preprint. doi:10.1101/ 042341

Edgar, R. C., Haas, B. J., Clemente, J. C., Quince, C., and Knight, R. 2011. UCHIME improves sensitivity and speed of chimera detection. Bioinformatics 27:2194-2200.

Egge, E., Bittner, L., Andersen, T., Audic, S., de Vargas, C., and Edvardsen, B. 2013. 454 pyrosequencing to describe microbial eukaryotic community composition, diversity and relative abundance: A test for marine haptophytes. PLoS ONE 8:e74371.

Giraldo, A., Gene, J., Sutton, D. A., Madrid, H., de Hoog, G. S., Cano, J., Decock, C., Crous, P. W., and Guarro, J. 2015. Phylogeny of Sarocladium (Hypocreales). Persoonia 34:10-24.

Gloor, G. B., and Reid, G. 2016. Compositional analysis: A valid approach to analyze microbiome high-throughput sequencing data. Can. J. Microbiol. 62: 692-703.

Gohl, D. M., Vangay, P., Garbe, J., MacLean, A., Hauge, A., Becker, A., Gould, T. J., Clayton, J. B., Johnson, T. J., Hunter, R., Knights, D., and Beckman, K. B. 2016. Systematic improvement of amplicon marker gene methods for increased accuracy in microbiome studies. Nat. Biotechnol. 34:942949.

Hannula, S. E., de Boer, W., and van Veen, J. 2012. A 3-year study reveals that plant growth stage, season and field site affect soil fungal communities while cultivar and GM-trait have minor effects. PLoS ONE 7:e3389.

Hyde, K. D., Nilsson, R. H., Alias, S. A., Ariyawansa, H. A., Blair, J. E., Cai, L., de Cock, A. W. A. M., Dissanayake, A. J., Glockling, S. L., Goonasekara, I. D., Gorczak, M., Hahn, M., Jayawardena, R. S., van Kan, J. A. L., Laurence, M. H., Levesque, C. A., Li, X., Liu, J.-K., Maharachchikumbura, S. S. N., Manamgoda, D. S., Martin, F. N., McKenzie, E. H. C., McTaggart, A. R., Mortimer, P. E., Nair, P. V. R., Pawlowska, J., Rintoul, T. L., Shivas, R. G., Spies, C. F. J., Summerell, B. A., Taylor, P. W. J., Terhem, R. B., Udayanga, D., Vaghefi, N., Walther, G., Wilk, M., Wrzosek, M., Xu, J.-C., Yan, J., and Zhou, N. 2014. One stop shop: Backbones trees for important phytopathogenic genera: I. Fungal Divers. 67:21-125.

Ichitani, T., Takamatsu, S., and Stamps, D. J. 1986. Identification and pathogenicity of three species of Pythium newly isolated from diseased wheat and barley just after thawing in Japan. Ann. Phytopathol. Soc. Jpn. 52: 209-216.

Iowa Environmental Mesonet. 2016. Iowa State University Department of Agronomy. Online resource. http://mesonet.agron.iastate.edu 
Kaspar, T. C., and Singer, J. W. 2011. The use of cover crops to manage soil. Pages 321-337 in: Soil Management: Building a Stable Base for Agriculture. J. L. Hatfield and T. J. Sauer, eds. American Society of Agronomy and Soil Science Society of America, Madison, WI.

Kaspar, T. C., Parkin, T. B., Jaynes, D. B., Cambardella, C. A., Meek, D. W., and Jung, Y. S. 2006. Examining changes in soil organic carbon with oat and rye cover crops using terrain covariates. Soil Sci. Soc. Am. J. 70:1168-1177.

Kerns, J. P., and Tredway, L. P. 2008a. Pathogenicity of Pythium species associated with Pythium root dysfunction of creeping bentgrass and their impact on root growth and survival. Plant Dis. 92:862-869.

Kerns, J. P., and Tredway, L. P. 2008b. Influence of temperature on pathogenicity of Pythium volutum toward creeping bentgrass. Plant Dis. 92: 1669-1673.

Kerns, J. P., Soika, M. D., and Tredway, L. P. 2009. Preventive control of Pythium root dysfunction in creeping bentgrass putting greens and sensitivity of Pythium volutum to fungicides. Plant Dis. 93:1275-1280.

Lee, S.-H., Kim, C.-G., and Kang, H. 2011. Temporal dynamics of bacterial and fungal communities in a genetically modified (GM) rice ecosystem. Microbiol. Ecol. 61:646-659.

Lindahl, B. D., Nilsson, R. H., Tedersoo, L., Abarenkov, K., Carlsen, T., Kjoller, R., Koljalg, U., Pennanen, T., Rosendahl, S., Stenlid, J., and Kauserud, H. 2013. Fungal community analysis by high-throughput sequencing of amplified markers-A user's guide. New Phytol. 199:288-299.

Lozupone, C. A., Hamady, M., Kelley, S. T., and Knight, R. 2007. Quantitative and qualitative $\beta$ diversity measures lead to different insights into factors that structure microbial communities. Appl. Environ. Microbiol. 73:1576-1585.

Lundberg, D. S., Lebeis, S. L., Paredes, S. H., Yourstone, S., Gehring, J., Malfatti, S., Tremblay, J., Engelbrektson, A., Kunin, V., del Rio, T. G., Edgar, R. C., Eickhorst, T., Ley, R. E., Hugenholtz, P., Tringe, S. G., and Dangl, J. L. 2012. Defining the core Arabidopsis thaliana root microbiome. Nature 488: 86-90.

Macfarlane, I. 1970. Lagena radicicola and Rhizophydium graminis, two common and neglected fungi. Trans. Br. Mycol. Soc. 55:113-116.

Manici, L. M., Caputo, F., and Babini, V. 2004. Effect of green manure on Pythium spp. population and microbial communities in intensive cropping systems. Plant Soil 263:133-142.

Mideros, S. X., Windham, G. L., Williams, W. P., and Nelson, R. J. 2009. Aspergillus flavus biomass in maize estimated by quantitative real-time polymerase chain reaction is strongly correlated with aflatoxin concentration. Plant Dis. 93:1163-1170.

Nishizawa, T., Zhaorigetu, Komatsuzaki, M., Sato, Y., Kaneko, N., and Ohta, H. 2010. Molecular characterization of fungal communities in non-tilled, covercropped upland rice field soils. Microbes Environ. 25:204-210.

Oksanen, J., Blanchet, F. G., Friendly, M., Kindt, R., Legendre, P., McGlinn, D., Minchin, P. R., O’Hara, R. B., Simpson, G. L., Solymos, P., Stevens, M. H. H., Szoecs, E., and Wagner, H. 2016. vegan: Community Ecology Package. R package version 2.4-1. https://CRAN.R-project.org/package $=$ vegan

Parkin, T. B., and Kaspar, T. C. 2006. Nitrous oxide emissions from cornsoybean systems in the Midwest. J. Environ. Qual. 35:1496-1506.

Peiffer, J. A., Spor, A., Koren, O., Jin, Z., Tringe, S. G., Dangl, J. L., Buckler, E. S., and Ley, R. E. 2013. Diversity and heritability of the maize rhizosphere microbiome under field conditions. Proc. Natl. Acad. Sci. USA 110:6548-6553.

Quast, C., Pruesse, E., Yilmaz, P., Gerken, J., Schweer, T., Yarza, P., Peplies, J., and Glockner, F. O. 2013. The SILVA ribosomal RNA gene database project: Improved data processing and web-based tools. Nucleic Acids Res. 41: D590-D596.

Quince, C., Lanzen, A., Davenport, R. J., and Turnbaugh, P. J. 2011. Removing noise from pyrosequenced amplicons. BMC Bioinformatics 12:38.
Redman, R. S., Sheehan, K. B., Stout, R. G., Rodriguez, R. J., and Henson, J. M. 2002. Thermotolerance generated by plant/fungal symbiosis. Science 298 : 1581.

Robideau, G. P., de Cock, A., Coffey, M. D., Voglmayr, H., Brouwer, H., Bala, K., Chitty, D. W., Desaulniers, N., Eggertson, Q. A., Gachon, C. M. M., Hu, C. H., Kupper, F. C., Rintoul, T. L., Sarhan, E., Verstappen, E. C. P., Zhang, Y. H., Bonants, P. J. M., Ristaino, J. B., and Levesque, C. A. 2011. DNA barcoding of oomycetes with cytochrome $\mathrm{c}$ oxidase subunit I and internal transcribed spacer. Mol. Ecol. Resour. 11:1002-1011.

Rognes, T., Flouri, T., Nichols, B., Quince, C., and Mahe, F. 2016. VSEARCH: A versatile open source tool for metagenomics. PeerJ 4:e2584.

Sapkota, R., and Nicolaisen, M. 2015. An improved high throughput sequencing method for studying oomycete communities. J. Microbiol. Methods 110:33-39.

Sati, S. C., Arya, P., and Belwal, M. 2009. Tetracladium nainitalense sp. nov., a root endophyte from Kumaun Himalaya, India. Mycologia 101:692-695.

Schisler, D. A., Boehm, M. J., Paul, P. A., Rooney, A. P., and Dunlap, C. A. 2015. Reduction of Fusarium head blight using prothioconazole and prothioconazole-tolerant variants of the Fusarium head blight antagonist Cryptococcus flavescens OH 182.9. Biol. Control 86:36-45.

Schloss, P. D., Westcott, S. L., Ryabin, T., Hall, J. R., Hartmann, M., Hollister, E. B., Lesniewski, R. A., Oakley, B. B., Parks, D. H., Robinson, C. J., Sahl, J. W., Stres, B., Thallinger, G. G., Horn, D. J. V., and Weber, C. F. 2009. Introducing Mothur: Open-source, platform-independent, communitysupported software for describing and comparing microbial communities. Appl. Environ. Microbiol. 75:7537-7541.

Schoch, C. L., Seifer, K. A., Huhndorf, S., Robert, V., Spouge, J. L., Levesque, C. A., and Chen, W., and Fungal Barcoding Consortium. 2012. Nuclear ribosomal internal transcribed spacer (ITS) region as a universal DNA barcode marker for fungi. Proc. Natl. Acad. Sci. USA 109:6241-6246.

Sugiyama, A., Ueda, Y., Zushi, T., Takase, H., and Yazaki, K. 2014. Changes in the bacterial community of soybean rhizospheres during growth in the field. PLoS ONE 9:e100709.

Tambong, J. T., de Cock, A., Tinker, N. A., and Levesque, C. A. 2006. Oligonucleotide array for identification and detection of Pythium species. Appl. Environ. Microbiol. 72:2691-2706.

Tsuji, M., Kudoh, S., and Hoshino, T. 2015. Draft genome sequence of cryophilic Basidiomycetous yeast Mrakia blollopis SK-4, isolated from an algal mat of Naga-ike Lake in the Skarvsnes ice-free area, East Antarctica. Genome Announc. 3:e01454-14.

Vannini, A., Bruni, N., Tomassini, A., Franceschini, S., and Vettraino, A. M. 2013. Pyrosequencing of environmental soil samples reveals biodiversity of the Phytophthora resident community in chestnut forests. FEMS Microbiol. Ecol. 85:433-442.

Vanterpool, T. C., and Ledingham, G. A. 1930. Studies on 'browning' root rot of cereals, I: The association of Lagena radicicola $\mathrm{n}$. gen.; $\mathrm{n}$. sp., with root injury of wheat. Can. J. Res. 2:171-194.

Vanterpool, T. C., and Truscott, J. H. L. 1932. Studies on browning root rot of cereals, II: Some parasitic species of Pythium and their relation to the disease. Can. J. Res. 6:68-93.

Wang, Q., Garrity, G. M., Tiedje, J. M., and Cole, J. R. 2007. Naïve Bayesian classifier for rapid assignment of rRNA sequences into the new bacterial taxonomy. Appl. Environ. Microbiol. 73:5261-5267.

Westcott, S. L., and Schloss, P. D. 2015. De novo clustering methods outperform reference-based methods for assigning 16S rRNA gene sequences to operational taxonomic units. PeerJ 3:e1487.

Yu, L., Nicolaisen, M., Larsen, J., and Ravnskov, S. 2012. Succession of rootassociated fungi in Pisum sativum during a plant growth cycle as examined by 454 pyrosequencing. Plant Soil 358:216-224. 